\title{
Falling into Holes in Our Sentences
}

This body holds its protective walls around us, it watches us whenever we walk out. Each step we take in conversation with our friends, moving slowly or flying, the body watches us, calling us into what is possible, into what is not said, into the shuckheap of ruined arrowheads, or the old man with missing fingers.

We take our first step in words each day, and instantly fall into a hole in our sounds. Overly sane afternoons in a room during our twenties come back to us in the form of a son who is mad, every longing another person had that we failed to see the body returns to us as a squinting of the eyes when we talk, and no sentimentality, only the ruthless body performing its magic, transforming each of our confrontations into energy, changing our scholarly labors over white-haired books into certainty and healing power, and our cruelties into an old man with missing fingers.

We talk all morning of the confusion of others, and in daylight the car slides off the road, I give advice in public as if I were mature, that night in a dream I see a policeman holding a gun to the head of a frightened girl, who is blindfolded, the priest talks easily of death, and opening a National Geographic sees an old woman lying with her mouth open.

\section{Robert Bly’s Sleepers Joining Hands: Shadow and Self / Michael Atkinson}

In Sleepers Joining Hands, Robert Bly offers his readers a various weave of the personal and the public, the psychological and the political modes of experience. Each mode illuminates the other, though, as I hope to show, the collection is most fundamentally and formally psychological. The layout of the book is pleasantly indirect: two dozen pages of poems, ranging from haiku-like meditation moments to longer poems of protest. Then there is the essay, a short course in the Great Mother, an analysis of the disturbing but finally nourishing configuration of feminine archetypes in the collective unconscious. And finally we have the oneiric title sequence: four poems and a coda, written at different times and published in different places, but here offered as a single structure, a whole.

The poems on either side of the essay seem to point back and forth to 